\title{
The Gap Between Evidence-Based Guidelines and Daily Practice: Cultural, Historical, and Financial Differences: Reply to Letter
}

\author{
René Holzheimer
}

Published online: 13 May 2010

(C) Société Internationale de Chirurgie 2010

Karem Slim [1] has demonstrated that despite evidencebased guidelines, primary inguinal hernia repair is driven by other factors, e.g., cultural and historical differences and financial considerations, in France and continental Europe. Why is it that two French societies give opposing directions for primary inguinal hernia repair [2, 3]? Is it "Nous sommes en France"? Is it the awareness that laparoscopic surgery was created in France? which, by the way, is not completely true [4]. We do not know, but there is some evidence that the decision to use laparoscopic techniques for primary inguinal hernia repair may be influenced by financial considerations in France. Laparoscopic inguinal hernia repair is performed mainly in private institutions and not in public hospitals, e.g., university clinics. Therefore, the statement that one third of inguinal hernia repairs in France are done laparoscopically may not prove that laparoscopic hernia repair is better; it just may reflect the structure and interests of the French health system. The argument to use a "modern" and not an "old" technique is no better. It is certainly important to include the laparoscopic technique in teaching hospitals, but this is not an aspect of evidence-based medicine. Thus, whether we can conclude that we know for sure that the chance of having an inguinal hernia repaired successfully in France is better than in the UK or US I could not say based on the information that I have. At the ISS meeting in Adelaide, Australia, I had the chance to ask Abe Fingerhut, who is a wellknown international laparoscopic surgeon, if he would favor laparoscopic inguinal hernia repair for primary inguinal hernia and he declined (A. Fingerhut, personal opinion, 2009).

\section{References}

1. Slim K (2010) The gap between evidence based guidelines and daily practice. World J Surg 34. doi:10.1007/s00268-010-0471-y

2. Peschaud F, Alves A, Berdah S et al (2009) Indications for laparoscopy in general and gastrointestinal surgery. Evidencebased recommendations of the French Society of Digestive Surgery. J Chir (Paris) 143:15-36

3. Champault G, Descottes B, Dulucq JL et al (2006) Laparoscopic surgery. The recommendations of specialty societies in 2006 (SFCL-SFCE). J Chir (Paris) 143:160-164

4. Mettler L, Semm K (1987) Diagnosis and conservative treatment of tubal pregnancy using pelviscopy in comparison with laparotomy. Geburtshilfe Frauenheilkd 47(10):717-720
R. Holzheimer $(\square)$

Hernia Clinic Sauerlach, Tegernseer Landstr. 8,

82054 Sauerlach, Munich, Germany

e-mail: rgholzheimer@t-online.de 